\title{
Tratamento de lixiviado por processos combinados: coagulação/floculação, air stripping, ozonização e lodo ativado
}

\author{
Leachate treatment by combined processes: \\ coagulation/flocculation, air stripping, ozonation and activated sludge
}

Alberto Dresch Webler ${ }^{1,2 *} \oplus$, Claudio Fernando Mahler ${ }^{2} \oplus$, Márcia Dezotti ${ }^{2} \odot$

\begin{abstract}
RESUMO
Os lixiviados de áreas de disposição de resíduos municipais apresentam, em geral, alta complexidade, variabilidade, toxicidade, recalcitrância e alta concentração de nitrogênio amoniacal. Neste estudo, aplicaram-se técnicas combinadas para o tratamento de um lixiviado, a saber: coagulação/ floculação (C/F), air stripping e ozonização, combinados com o tratamento por lodo ativado com/sem inserção de carvão ativado. O processo de C/F levou a uma redução na demanda química de oxigênio (DQO) de 58,1\% e na cor, de 85,6\%. O air stripping foi realizado em pH>12 e obteve-se diminuição dos níveis de nitrogênio amoniacal para abaixo de 60 mg. L'-1. O processo de ozonização, com consumo de ozônio de 397 mgO . $^{-1}{ }^{-1}$ e 2.376 mgO ${ }_{3} \mathrm{~L}^{-1}$, apresentou bons resultados, com aumento de 59,4\% na relação $\mathrm{DBO}_{5} / \mathrm{DQO}$ e uma redução de toxicidade superior a $85 \%$. Obteve-se melhor eficiência para o lodo ativado sem carvão ativado, com lixiviado pré-tratado por C/F + air stripping + ozonização (400 mgO $\left.\mathrm{L}^{-\mathrm{L}^{\prime}}\right)$. Tal combinação resultou em uma redução de 90,6\% na DQO do lixiviado e mais de 99\% nos níveis de nitrogênio amoniacal. Palavras-chave: lixiviado; toxicidade; biodegradabilidade; ozônio.
\end{abstract}

\begin{abstract}
Leachate from waste disposal areas generally presents high complexity, variability, toxicity, recalcitrance and high concentration of ammonia nitrogen. In this work, combined techniques for the treatment of leachate were applied, namely: coagulation/flocculation, air stripping and ozonation combined with activated sludge treatment with/without activated carbon. The coagulation/flocculation process led to a COD reduction of $58.1 \%$ and color removal of $85.6 \%$. The air stripping was performed at $\mathrm{pH}>12$ and reduced ammonia levels below of $60 \mathrm{mg} . \mathrm{L}^{-1}$. The ozonation process (ozone consumption of $397 \mathrm{mgO}_{3} \mathrm{~L}^{-1}$ and $2376 \mathrm{mgO}_{3} \mathrm{~L}^{-1}$ ) presented good results. It was observed $a \mathrm{BOD}_{5} / \mathrm{COD}$ increase of $59.4 \%$ and a toxicity reduction of more than $85 \%$. The best efficiency was observed with sludge activated without activated carbon for the pre-treated leachate by coagulation/ flocculation + air stripping + ozonation $\left(400 \mathrm{mgO}_{3} \mathrm{~L}^{-1}\right)$. This combination resulted in a COD reduction of $90.6 \%$ and more than $99 \%$ of ammonia nitrogen removal.
\end{abstract}

Keywords: leachate; toxicity; biodegradability; ozone.

\section{INTRODUÇÃO}

No Brasil, o método mais empregado pelas empresas que coletam e dispõem os resíduos sólidos urbanos (RSU) ainda é o dos aterros, devido às pretensas vantagens quanto à simplicidade e ao baixo custo no curto prazo. Não obstante, um dos inconvenientes dos aterros de rejeitos é a produção de lixiviado, cujo tratamento adequado pode representar um acréscimo significativo no custo total de disposição dos detritos (SILVA et al., 2016).

O lixiviado de um aterro de resíduos sólidos apresenta, normalmente, elevados valores de demanda química de oxigênio (DQO), demanda bioquímica de oxigênio $\left(\mathrm{DBO}_{5}\right)$, concentração de nitrogênio amoniacal, toxicidade e recalcitrância, dificultando o tratamento por processos biológicos, principalmente no caso de aterros antigos (AMOR et al., 2015; ZHANG et al., 2017). Assim, é necessário o emprego de tratamentos prévios para reduzir os altos níveis de DQO, nitrogênio amoniacal, toxicidade e aumentar a relação $\mathrm{DBO}_{5} / \mathrm{DQO}$, entre outros (LI et al., 2010; AMR et al., 2013; CORTEZ et al., 2011; MOREIRA et al., 2016; ZHOU et al., 2016), para um posterior tratamento biológico.

Diversos métodos físico-químicos vêm apresentando bons resultados, tais como coagulação/floculação (C/F) (MARAÑón et al., 
2008; MAHMUD; HOSSAIN; SHAMS, 2012; SYAFALNI et al., 2012; LIU et al., 2012), air stripping (WISZNIOWSKI et al., 2007; GUO et al., 2010), processos oxidativos avançados (CORTEZ et al., 2011; ANFRUNS et al., 2013; SILVA et al., 2016), processos eletroquímicos avançados (MOREIRA et al., 2016), evaporação (PALMA et al., 2002; BIALOWIEC; BARYLA; AGOPSOWICZ, 2007), precipitação química (LI; ZHAO; HAO, 1999; ZHANG; DING; REN, 2009) e membranas (SINGH; TOWNSEND; BOYER, 2012).

Vale ressaltar que não há um único procedimento de tratamento para um lixiviado de aterro sanitário, sendo necessária a combinação de processos para propiciar um tratamento adequado (ZHANG et al., 2012, MOREIRA et al., 2016, SILVA et al., 2016, HUANG et al., 2017).

Neste estudo, foi avaliada uma combinação de tratamentos, incluindo processos físico-químicos como C/F, air stripping, ozonização e lodos ativados, com o intuito de obter um lixiviado com os níveis adequados de DQO e nitrogênio amoniacal para o seu descarte.

\section{MATERIAIS E MÉTODOS}

\section{Lixiviado}

O lixiviado foi coletado em um aterro de resíduos sólidos localizado no Estado do Rio de Janeiro em operação há mais de 20 anos. Inicialmente, ele foi operado como lixão, passando a ter, por volta do ano de 2005, um sistema de operação conforme um aterro controlado. Atualmente, apresenta apenas algumas células em operação com características de aterro sanitário.

O lixiviado, após a coleta, foi mantido em temperatura de $4^{\circ} \mathrm{C}$, de acordo com a American Public Health Association (APHA), a American Water Works Association (AWWA) e a Water Pollution Control Federation (WPCF). (2005), armazenado em uma câmara fria e caracterizado posteriormente.

Os parâmetros analisados foram $\mathrm{pH}, \mathrm{DQO}, \mathrm{DBO}_{5}, \mathrm{NH}_{4}^{+}, \mathrm{N}$, sólidos suspensos voláteis (SSV), sólidos suspensos totais (SST) e cor, os quais foram determinados de acordo com o Standard Methods for the Examination of Water and Wastewater (APHA; AWWA; WPCF, 2005). $\mathrm{O}$ pH foi medido usando pHmetro da marca Digimed, modelo DM 23. A DQO foi determinada pelo método AWWA 5220B, utilizando um termo-digestor (Policontrol) e o espectrofotômetro (HACH DR-2800). A determinação de SST e SSV foi realizada pelos métodos AWWA $2540 \mathrm{D}$ e 2540E. A cor foi mensurada de acordo com o método padrão Platinum-Cobalt, AWWA 2120C. O teor de carbono orgânico dissolvido (COD) das amostras foi medido em um analisador de carbono orgânico total (COT) Shimadzu 5000A. O método é baseado na combustão catalítica, à alta temperatura $\left(680^{\circ} \mathrm{C}\right)$, e o $\mathrm{CO}_{2}$ formado foi quantificado por um detector de infravermelho não dispersivo. As amostras foram previamente filtradas em uma membrana de éster de celulose de porosidade média de $0,45 \mu \mathrm{m}$ da marca Milipore.

\section{Coagulação/floculação}

Esses ensaios foram realizados em triplicata utilizando cloreto férrico hexahidratado $\left(\mathrm{FeCl}_{3} \cdot 6 \mathrm{H}_{2} \mathrm{O}\right)$, da marca VETEC, em um equipamento Jar Test, da marca Digimed, equipado para seis ensaios simultâneos. Para cada teste, utilizou-se um volume de $1 \mathrm{~L}$ de lixiviado.

Durante os ensaios foram variados o $\mathrm{pH}$ ( 4 a 9), a dosagem de coagulante (400 e 900 mg. $\mathrm{L}^{-1)}$ e uma concentração de polímero iônico com $4 \mathrm{mg} . \mathrm{L}^{-1}$. Para ajuste do $\mathrm{pH}$, utilizou-se uma solução de hidróxido de sódio $(\mathrm{NaOH})$ ou ácido sulfúrico $\left(\mathrm{H}_{2} \mathrm{SO}_{4}\right)$.

As amostras, após a adição do cloreto férrico, foram submetidas à agitação rápida (150 rpm) por 5 minutos. Em seguida, foi adicionado o polímero iônico e foram submetidas à agitação lenta $(30 \mathrm{rpm})$ por 15 minutos. Após a mistura lenta, as amostras ficaram em repouso por 30 minutos.

Foi realizada uma análise estatística dos dados de C/F por meio do teste Kruskal-Wallis, pois alguns pressupostos primordiais, como normalidade e variância, constantes nos dados não foram atendidos. De acordo com Theodorsson-Norheim (1986), quando um desses pressupostos não é atendido, esse teste é uma excelente alternativa. Quando os resultados com ele foram significativos, utilizou-se o teste Dunn (1964) para comparações dos tratamentos dois a dois. Os testes foram realizados no programa R (R CORE TEAM, 2017).

\section{Air Stripping}

Para os ensaios de remoção de nitrogênio amoniacal, foram usadas seis provetas de $2 \mathrm{~L}$ e o lixiviado em $\mathrm{pH}>12$. Para o processo de arraste, utilizou-se uma bomba de ar comprimido com vazão de 1,2 L.min ${ }^{-1}$. Para o borbulhamento de ar, foi empregada uma pedra porosa. $\mathrm{O}$ arraste foi mantido até a concentração de nitrogênio amoniacal decair a valores próximos de $60 \mathrm{mg} . \mathrm{L}^{-1}$.

\section{Ozonização}

Para a produção do ozônio, utilizou-se um gerador da marca Multivácuo, modelo MV06. O ozônio foi produzido a partir de oxigênio puro com uma vazão de 1 L.min ${ }^{-1}$. A quantidade de ozônio produzida foi medida em todos os ensaios por meio do seu borbulhamento direto em um frasco lavador de gás em uma solução de iodeto de potássio (KI) $2 \%$, usando um volume de $200 \mathrm{~mL}$ por 2 minutos. O mesmo método foi usado para determinar a quantidade de ozônio não consumida nos ensaios de ozonização do lixiviado. Para tanto, utilizou-se o método 2350E do Standard Methods for the Examination of Water and Wastewater (APHA; AWWA; WPCF, 2005).

\section{Toxicidade}

Para o ensaio de toxicidade, foi utilizado o equipamento Microtox. O organismo utilizado foi Vibrio fisheri (bactéria de origem marinha que emite luz naturalmente). Para a realização do teste, foi usada uma 
amostra de $1 \mathrm{~mL}$ de efluente, que era exposta a essas bactérias. $\mathrm{O}$ efeito foi medido com 15 minutos de teste, quando se observou a redução da luminosidade emitida conforme a ABNT NBR 15411-3 (ABNT, 2012).

\section{Lodos ativados}

O lodo biológico empregado foi proveniente de uma estação de tratamento de esgoto sanitário da cidade do Rio de Janeiro. Os ensaios foram realizados em provetas de $2 \mathrm{~L}$, utilizando um volume de $1 \mathrm{~L}$, com proporção de $200 \mathrm{~mL}$ de lodo biológico e $800 \mathrm{~mL}$ de efluente. Os testes foram realizados em regime de batelada com duração média de 24 horas. Para a aeração, foi utilizada uma bomba de ar com vazão de $1,2 \mathrm{~L} \cdot \mathrm{m}^{-1}$.

Foram realizados três conjuntos de ensaios em batelada com diferentes amostras pré-tratadas, sempre com o mesmo volume $(1 \mathrm{~L})$.

O percentual de redução de DQO, considerando apenas a degradação do lixiviado, foi calculado conforme as Equações 1, 2, 3 e 4:

$\mathrm{DQO}_{\text {lix }} \cdot \mathrm{V}_{\text {lix }}=\mathrm{DQO}_{\text {Alix }}$

Em que:

$\mathrm{DQO}_{\text {lix }}=$ DQO do lixiviado $\left(\mathrm{mgO}_{2} \cdot \mathrm{L}^{-1}\right)$;

$\mathrm{V}_{\text {lix }}=$ volume de lixiviado inserido no reator $(\mathrm{L})$;

$\mathrm{DQO}_{\text {Alix }}=\mathrm{DQO}$ aplicada de lixiviado $\left(\mathrm{mgO}_{2} \cdot \mathrm{L}^{-1}\right)$.

$\mathrm{DQO}_{\text {res }} \cdot \mathrm{V}_{\text {res }} \cdot \mathrm{C}_{\text {água }}=\mathrm{DQO}_{\text {Ares }}$

Em que:

$\mathrm{DQO}_{\text {res }}=\mathrm{DQO}$ restante do dia anterior $\left(\mathrm{mgO}_{2} \cdot \mathrm{L}^{-1}\right)$;

$\mathrm{V}_{\text {res }}=$ volume de efluente residual do dia anterior $(\mathrm{L})$;

$\mathrm{C}_{\text {água }}=$ percentual de efluente no volume residual (\%);

$\mathrm{DQO}_{\text {Ares }}=\mathrm{DQO}$ residual $\left(\mathrm{mgO}_{2} \cdot \mathrm{L}^{-1}\right)$.

$\mathrm{DQO}_{\text {esg }}=\mathrm{DQO}_{\text {ini }}-\left(\mathrm{DQO}_{\text {Alix }}+\mathrm{DQO}_{\text {Ares }}\right)$

Em que:

$\mathrm{DQO}_{\text {esg }}=\mathrm{DQO}$ do esgoto $\left(\mathrm{mgO}_{2} \cdot \mathrm{L}^{-1}\right)$;

$\mathrm{DQO}_{\mathrm{ini}}=\mathrm{DQO}$ no início diário do teste $\left(\mathrm{mgO}_{2} \cdot \mathrm{L}^{-1}\right)$;

$\mathrm{DQO}_{\text {Alix }}=\mathrm{DQO}$ aplicada de lixiviado $\left(\mathrm{mgO}_{2} \cdot \mathrm{L}^{-1}\right)$;

$\mathrm{DQO}_{\text {Ares }}=$ DQO residual $\left(\mathrm{mgO}_{2} \cdot \mathrm{L}^{-1}\right)$.

$\mathrm{DQO}_{\text {Alix }} \cdot \mathrm{E}_{\text {lix }}+\mathrm{DQO}_{\text {esg }} \cdot \mathrm{E}_{\mathrm{esg}}+\mathrm{DQO}_{\text {Ares }} \cdot \mathrm{E}_{\mathrm{res}}=\mathrm{DQO}_{\text {saída }}$

Em que:

$\mathrm{DQO}_{\text {Alix }}=\mathrm{DQO}$ aplicada de lixiviado $\left(\mathrm{mgO}_{2} \cdot \mathrm{L}^{-1}\right)$;

$\mathrm{E}_{\text {lix }}$ : eficiência de redução de DQO do lixiviado (\%);

$\mathrm{DQO}_{\text {esg }}=\mathrm{DQO}$ do esgoto $\left(\mathrm{mgO}_{2} \cdot \mathrm{L}^{-1}\right)$;

$\mathrm{E}_{\text {esg }}=$ eficiência de redução de DQO do esgoto (\%);
$\mathrm{DQO}_{\text {Ares }}=\mathrm{DQO}$ residual $\left(\mathrm{mgO}_{2} \cdot \mathrm{L}^{-1}\right)$;

$\mathrm{E}_{\text {res }}=$ eficiência de redução de DQO do esgoto (\%);

$\mathrm{DQO}_{\text {saía }}=\mathrm{DQO}$ no início diário do teste $\left(\mathrm{mgO}_{2} \cdot \mathrm{L}^{-1}\right)$.

Para o cálculo, foram feitas as seguintes hipóteses: $\mathrm{E}_{\text {res }}$ igual a 1, ou seja, constante. Dessa forma, o que não foi degradado no dia anterior permanecerá com a mesma DQO, sendo que apresentou em média $29 \mathrm{mgO}_{2} \cdot \mathrm{L}^{-1}$. Foi adotado a $\mathrm{C}_{\text {água }}$ igual a 0,6 , uma vez que $60 \%$ do volume do lodo é a fração líquida, sendo, inicialmente, a DQO considerada igual a zero, e nos demais dias, a DQO do fim do teste. Para os valores de $\mathrm{E}_{\text {esg }}$, foi considerada a média do período dos reatores $\mathrm{A}, \mathrm{B}$ e C, respectivamente.

Foram realizados ensaios em batelada com amostras pré-tratadas por $\mathrm{C} / \mathrm{F}$, air stripping e ozonização, sendo executados seis testes com diferentes processos, designados A1, A2, B1, B2, C1 e C2. Nos testes $\mathrm{C} 1$ e C2, foram inseridos $2 \mathrm{~g}$ de carvão ativado no reator biológico sem renovação. A Figura 1 apresenta as combinações e o ordenamento dos ensaios realizados para o tratamento do lixiviado.

\section{RESULTADOS E DISCUSSÃO}

Na Tabela 1, são apresentadas as características físico-químicas do lixiviado utilizado. Observa-se que há valores altos para DQO e nitrogênio amoniacal, muito superiores aos estabelecidos pelo Conselho Nacional de Meio Ambiente (CONAMA), de acordo com a Resolução $\mathrm{n}^{\circ} 430$ de 2011 (BRASIL, 2011), e pela Resolução do Instituto Estadual do Ambiente (INEA), NT-202, para o descarte de efluentes (RIO DE JANEIRO, 1986).

Entre os parâmetros analisados, o nitrogênio, principalmente na forma amoniacal, o COD e a DQO são expressivos. Vale destacar que o nitrogênio amoniacal é altamente tóxico. $\mathrm{O}$ valor da razão $\mathrm{DBO}_{5} / \mathrm{DQO}$ do lixiviado foi 0,33 , o que indica que o efluente apresenta caráter recalcitrante e abaixo do recomendável, de 0,5 , para empregar um processo biológico (RENOU et al., 2008). Isso, conjuntamente com a alta concentração de nitrogênio amoniacal, desfavorece um tratamento biológico, sendo necessário um tratamento primário para a remoção do nitrogênio amoniacal e aumentar a biodegradabilidade do lixiviado (VEDRENNE et al., 2012).

\section{Testes de coagulação/floculação}

A aplicação de um processo de $\mathrm{C} / \mathrm{F}$ como processo primário foi realizada para promover a remoção de parte da matéria orgânica recalcitrante, como substâncias húmicas. Por causa do teor elevado de cor, Velasquez e Ramirez (2006) sugerem que mais de 90\% da cor do lixiviado é devido à presença de ácidos húmicos.

Para os testes, foi utilizado como coagulante o $\mathrm{FeCl}_{3}$, que apresentou bons resultados em Amor et al. (2015), Bila (2000) e 
Theepharaksapan et al. (2011), com eficiência de redução de DQO de 63,43 e $31,48 \%$, respectivamente.

Os ensaios de $\mathrm{C} / \mathrm{F}$ em diferentes valores de $\mathrm{pH}$ e concentrações de coagulante são apresentados na Figura 2. A maior remoção de cor e DQO ocorreu em pH 5, com a atenuação de 79,1\% e de $61 \%$, respectivamente (Figura $2 \mathrm{~A}$ ). Esses valores estão próximos aos encontrados por Li et al. (2010), os quais relatam que, em pH 5,5, houve uma remoção de COD de 65\%.

À medida que o pH se torna ácido, uma melhora na redução de cor e DQO é observada. Isso ocorre por causa da reação dos íons férricos com a hidroxila $\left(\mathrm{OH}^{-}\right)$, resultando em $\mathrm{Fe}(\mathrm{OH})_{3}$ ou $\mathrm{Fe}(\mathrm{OH})_{4}^{-}$na condição básica. Já na condição ácida, os íons férricos podem ser hidrolisados em cátions polinucleares na forma de $\mathrm{Fe}(\mathrm{OH})_{\mathrm{y}}^{(3 \mathrm{x}-\mathrm{y})}$, podendo se apresentarem as formas $\mathrm{Fe}_{2}(\mathrm{OH})^{2+}, \mathrm{Fe}_{3}(\mathrm{OH})_{2}{ }^{4+}, \mathrm{Fe}_{3}(\mathrm{OH})_{4}{ }^{5+}$ e algumas outras formas. Nesse caso, os cátions polinucleares são preferíveis a $\mathrm{Fe}(\mathrm{OH})_{3}$ ou $\mathrm{Fe}(\mathrm{OH})_{4}^{-}$, pois as impurezas coloidais, em geral, apresentam cargas negativas (CHING; TANAKA; ELIMELECH, 1994; LI et al., 2010).

Ao aplicar o teste não paramétrico Kruskal-Wallis, detectou-se uma diferença ao variar o $\mathrm{pH}$, para redução de DQO e cor $(\mathrm{p}<0,01031$ e $\mathrm{p}<0,01103$, respectivamente). Como no teste de Kruskal-Wallis obteve-se uma diferença, buscou-se verificar quais $\mathrm{pH}$ são estatisticamente iguais e, para tal análise, foi aplicado o teste de Dunn. Esse teste identificou que, sob pH 7, 8 e 9, a redução de DQO e cor foi significativamente semelhante.

Na variação da dosagem de coagulante, apresentada na Figura 2B, obteve-se melhor remoção de cor (89\%), com uma concentração de
$\mathrm{FeCl}_{3}$ de 400 mg.L $\mathrm{L}^{-1}$, enquanto a maior eficiência de remoção de DQO (58\%) foi obtida com a concentração de $\mathrm{FeCl}_{3}$ de $700 \mathrm{mg} \cdot \mathrm{L}^{-1}$.

Através do teste Kruskal-Wallis, observou-se que houve diferença na redução de cor entre as concentrações estudadas (valor $\mathrm{p}<0,00369$ ), mas não na redução de DQO. Na aplicação do teste de Dunn, observou-se que a concentração de $600 \mathrm{mg} \cdot \mathrm{L}^{-1}$ foi estatisticamente igual à de 400 mg.L $L^{-1}$ e 700 mg.L. $L^{-1}$ de $\mathrm{FeCl}_{3}$, contudo a concentração de 400 mg.L $\mathrm{L}^{-1}$

Tabela 1 - Características físico-químicas do lixiviado bruto.

\begin{tabular}{|c|c|c|c|}
\hline Variável & Unidades & $1^{\mathrm{a}}$ amostra & $2^{\mathrm{a}}$ Amostra \\
\hline DQO & $\mathrm{mg} \cdot \mathrm{L}^{-1}$ & 2.595 & 2.340 \\
\hline DQO filtrada & $\mathrm{mg} \cdot \mathrm{L}^{-1}$ & 2.365 & 2.050 \\
\hline $\mathrm{DBO}_{5}$ & $\mathrm{mg} \cdot \mathrm{L}^{-1}$ & 870 & ND \\
\hline SST & $\mathrm{mg} \cdot \mathrm{L}^{-1}$ & 116,20 & 145,30 \\
\hline SSV & $m g . L^{-1}$ & 107,85 & 127,50 \\
\hline COD & $m g \cdot L^{-1}$ & 603 & 883 \\
\hline Nitrogênio amoniacal & $\mathrm{mg} \cdot \mathrm{L}^{-1}$ & 1.818 & 1.856 \\
\hline Nitrogênio total & $\mathrm{mg} \cdot \mathrm{L}^{-1}$ & 1.954 & ND \\
\hline Cloreto & $m g . L^{-1}$ & 2.248 & 1.975 \\
\hline Condutividade & $\mu \mathrm{s} . \mathrm{cm}^{-1}$ & 14.793 & 16.891 \\
\hline Cor & mgPtCo. $L^{-1}$ & 1.640 & 1.790 \\
\hline $\mathrm{pH}$ & - & 8,67 & 8,36 \\
\hline
\end{tabular}

DQO: demanda química de oxigênio; $\mathrm{DBO}_{5}$ : demanda bioquímica de oxigênio SST: sólidos suspensos totais; SSV: sólidos suspensos voláteis; COD: carbono orgânico dissolvido.

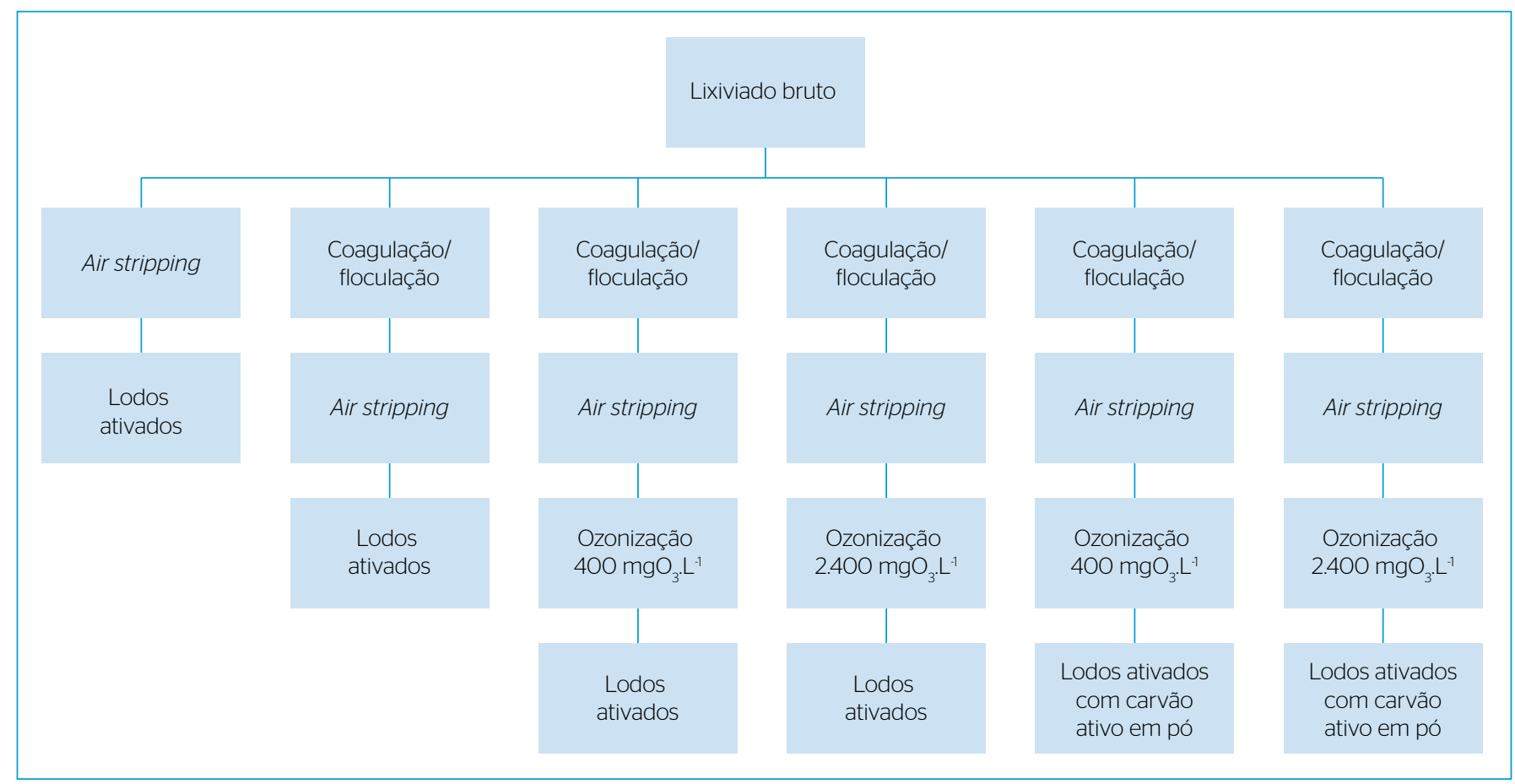

Figura 1 - Diagrama e ordenamento dos ensaios realizados para o tratamento de lixiviado. 
difere apenas com a de $700 \mathrm{mg} . \mathrm{L}^{-1}$. Assim, optou-se pela dosagem de $600 \mathrm{mg} . \mathrm{L}^{-1}$ de $\mathrm{FeCl}_{3}$, pois essa concentração de coagulante é estatisticamente igual às melhores dosagens, com eficiência de $85,6 \%$ para a cor e de $58,1 \%$ para a DQO.

\section{Air stripping}

O air stripping visou remover o nitrogênio amoniacal através da elevação do $\mathrm{pH}$, já que, em meio alcalino, ocorre a conversão de $\mathrm{NH}_{4}{ }^{+}$para $\mathrm{NH}_{3}$. Assim, elevou-se o $\mathrm{pH}$ das amostras para valores superiores a 12, com o objetivo de alcançar um valor de nitrogênio amoniacal próximo a $60 \mathrm{mg} \cdot \mathrm{L}^{-1}$. Obteve-se remoção de DQO de $8 \%$ do lixiviado pré-tratado por C/F.

A remoção de nitrogênio amoniacal obtida neste trabalho foi de $96,7 \%$, valores próximos aos encontrados por Guo et al. (2010) e Hasar et al. (2009), que obtiveram remoções de 96,6\% em pH 11 e 93,2\% em $\mathrm{pH} 12$, respectivamente. Ambos os estudos relatam teores de $\mathrm{NH}_{4}^{+}$no lixiviado bruto acima de $1.100 \mathrm{mg} \cdot \mathrm{L}^{-1}$.

\section{Ozonização}

O ozônio pode ser utilizado em um tratamento combinado, com possibilidade de diversas perspectivas e objetivos. A aplicação do ozônio no lixiviado em $\mathrm{pH} 7$ foi realizada, lembrando que, nesse $\mathrm{pH}$, dois mecanismos de oxidação estão presentes: o direto, através da ação do ozônio molecular, e o indireto, através do radical hidroxila. Ambos os mecanismos (direto e indireto) podem ser relevantes (GOTTSCHALK; LIBRA; SAUPE, 2010; IACONI, 2012).
A aplicação do ozônio antes de um processo biológico pode favorecer uma redução de DQO no processo biológico, devido ao aumento da biodegradabilidade (degradação dos ácidos húmicos e modificação de compostos que podem ser tóxicos e recalcitrantes aos processos biológicos) (SOBECKA; TOMASZEWSKA MORAWSKI, 2006; SANTOS et al., 2013; BILIŃSKA; GMUREK; LEDAKOWICZ, 2016).

Na Figura 3, são apresentados os resultados da ozonização do lixiviado que passou pelos processos de $\mathrm{C} / \mathrm{F}$ e air stripping, com enfoque na redução de DQO e no aumento da biodegradabilidade ( $\left.\mathrm{DBO}_{5} / \mathrm{DQO}\right)$.

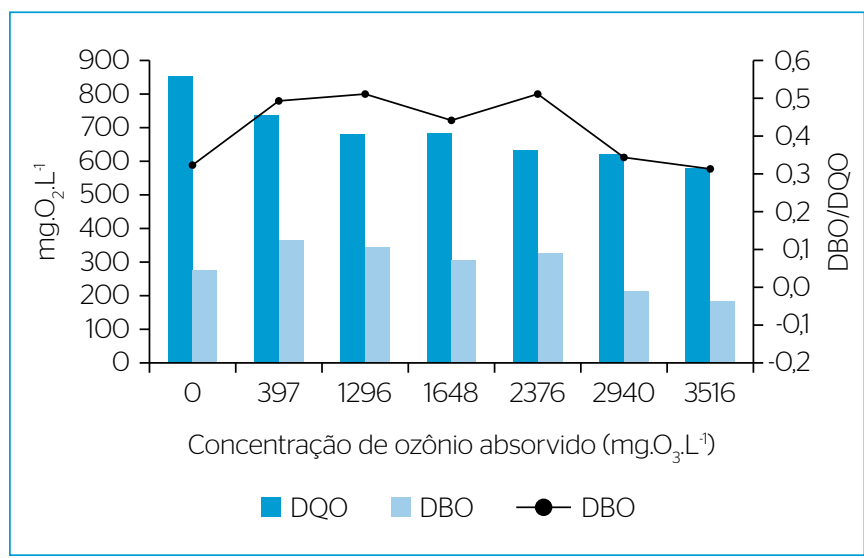

Figura 3 - Demanda química de oxigênio, demanda bioquímica de oxigênio e razão $\mathrm{DBO}_{5} / \mathrm{DQO}$ para amostras ozonizadas com diferentes doses de ozônio absorvido.

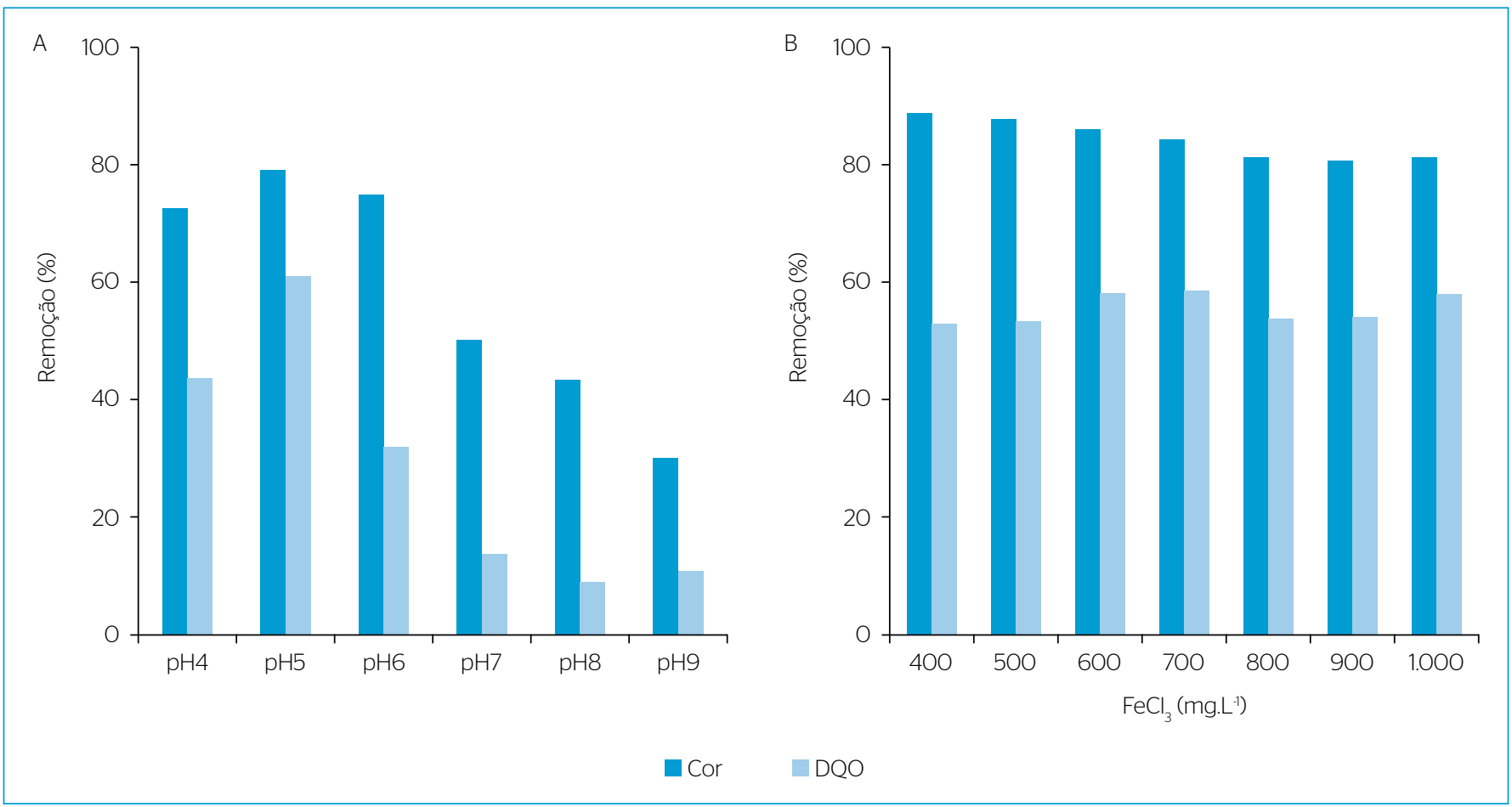

Figura 2 - Eficiência do processo de coagulação/floculação na remoção de cor e demanda química de oxigênio em diferentes $\mathrm{pH}\left(700 \mathrm{mg} \cdot \mathrm{L}^{-1}\right.$ de $\mathrm{FeCl}$ ) (A) e concentrações de cloreto férrico $\left(\mathrm{mg}^{\mathrm{L}} \mathrm{L}^{-1}\right)(\mathrm{pH}=5)(B)$. 
Pode-se observar que ocorreu uma redução de DQO entre 13,7 e 32,1\% com uma dose de ozônio consumido de 397 a $3.516 \mathrm{mgO}_{3} \cdot \mathrm{L}^{-1}$. Já a $\mathrm{DBO}_{5}$ apresentou inicialmente um acréscimo de 33,8\% (397 $\left.\mathrm{mgO}_{3} \cdot \mathrm{L}^{-1}\right)$, mas, posteriormente, começou a decrescer, com uma redução de $33,1 \%$ com a aplicação de $\mathrm{O}_{3}$ de $3.516 \mathrm{mgO}_{3} \cdot \mathrm{L}^{-1}$. Consequentemente, a relação $\mathrm{DBO}_{5} / \mathrm{DQO}$ se comportou similarmente à $\mathrm{DBO}_{5}$. Os melhores resultados foram obtidos com aplicação de $\mathrm{O}_{3}$ entre 397 e $2.376 \mathrm{mgO}_{3} \cdot \mathrm{L}^{-1}$, com uma relação $\mathrm{DBO}_{5} / \mathrm{DQO}$ média de 0,49 , valor $53 \%$ superior ao da amostra não ozonizada, que apresentava 0,32 .

Assim, a ozonização, além de reduzir a DQO, propiciou aumento da relação $\mathrm{DBO}_{5} / \mathrm{DQO}$, que indica um aumento na biodegrabilidade desse lixiviado.

Outro parâmetro analisado foi a cor (Figura 4), que é altamente dependente das características do lixiviado, como a presença de substâncias húmicas. Assim, a redução da cor pode ser atribuída ao ataque do ozônio a compostos aromáticos ou a ligações duplas que, provavelmente, são responsáveis pela cor do lixiviado (GOTTSCHALK; LIBRA; SAUPE, 2010).

Os resultados denotam uma redução de cor de $85 \%$ com o consumo de $3.516 \mathrm{mgO}_{3} \cdot \mathrm{L}^{-1} \mathrm{e}$ de $64 \%$ com o consumo de $397 \mathrm{mgO}_{3} \cdot \mathrm{L}^{-1}$. Assim, a remoção de cor e DQO pelos processos combinados de C/F (85,6 e 58,1\%), air stripping (2,9 e 5,5\%) e ozonização com $3.516 \mathrm{mgO}_{3} \cdot \mathrm{L}^{-1}$ $(9,92$ e $11,7 \%)$ foi de 98,4 e de $75,3 \%$, respectivamente, em relação ao lixiviado bruto.

A fim de escolher a melhor dosagem de ozônio, levou-se em consideração a razão de $\mathrm{DBO}_{5} / \mathrm{DQO}$, juntamente com a dose de ozônio consumido. Dessa forma, foram escolhidas as doses de ozônio consumido de 397 e $2.376 \mathrm{mgO}_{3} \cdot \mathrm{L}^{-1}$ para os ensaios biológicos.

Cassano et al. (2011) utilizaram o processo biológico com reator granular sequencial em batelada, o qual apresentou eficiência média sem a ozonização de 54\% (1.200 para $\left.552 \mathrm{mg} . \mathrm{L}^{-1}\right)$ na remoção de DQO e, com a aplicação de ozônio com taxa de 400 e $1.600 \mathrm{mgO}_{3} \cdot \mathrm{L}^{-1}$, foi

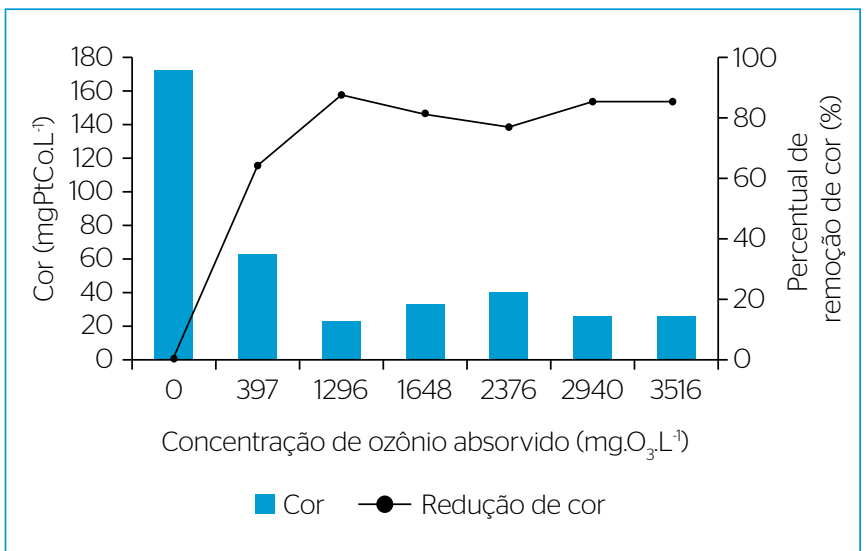

Figura 4 - Remoção de cor para amostras de lixiviado (pré-tratado por coagulação/floculação e air stripping) por ozonização com diferentes doses de ozônio absorvido. obtida eficiência global de 85\% (1.200 para 180 mg.L $\left.\mathrm{L}^{-1}\right)$ e $95 \%$ (1.200 para $\left.60 \mathrm{mg} . \mathrm{L}^{-1}\right)$, respectivamente.

\section{Toxicidade}

Um lixiviado proveniente de disposição de resíduos sólidos é composto de uma gama de constituintes que podem apresentar um risco potencial, quando liberados no meio ambiente, por serem potencialmente tóxicos e resistentes à degradação no meio ambiente (ZOLFAGHARI et al., 2016; BACCOT et al., 2017). Assim, o ensaio de toxicidade aguda possibilita indicar a redução de toxicidade alcançada nos processos de tratamento avaliados neste estudo. A toxicidade do lixiviado bruto para Vibrio fisheri é apresentada na Tabela 2.

Observa-se que o lixiviado apresentou toxicidade. Os resultados obtidos são próximos aos encontrados no lixiviado do aterro de Gramacho, na cidade do Rio de Janeiro (CE50\% entre 11,27 e 15,02\%) (SILVA; DEZOTTI; SANT'ANNA, 2004) e do aterro em Apulia, na região Sudeste da Itália (CE50\% entre 13 e 18\%) (CASSANO et al., 2011), utilizando o mesmo organismo.

O tratamento por C/F apresentou uma pequena redução de 3,5\% na toxicidade (Tabela 2), diferindo nos estudos realizados por Silva, Dezotti e Sant'anna (2004), que mostraram um aumento da toxicidade, possivelmente por conta da utilização de sulfato de alumínio $\mathrm{Al}_{2}\left(\mathrm{SO}_{4}\right)_{3}$ como coagulante no processo de $\mathrm{C} / \mathrm{F}$ do lixiviado.

Entre os inúmeros compostos presentes nos lixiviados que causam toxicidade, o nitrogênio amoniacal merece destaque, principalmente devido aos elevados níveis aqui encontrados (1818 mg.L-1). Assim, ao remover o nitrogênio amoniacal para concentrações abaixo de $60 \mathrm{mg} . \mathrm{L}^{-1}$, por air stripping, juntamente com a C/F, a CE50\% aumentou em 76,8\% (de 18,27 para $32,3 \%$ ).

Os resultados para os ensaios de toxicidade do lixiviado após a ozonização são apresentados na Tabela 3. Observa-se aumento na CE50\% em 173 e 165\%, com ozônio consumido de 397 e 1.296 mgO $_{3} \mathrm{~L}^{-1}$, comparando-se as amostras tratadas por $\mathrm{C} / \mathrm{F}+$ air stripping. Além disso, quando a concentração absorvida de ozônio foi entre 1.648 e $3.516 \mathrm{mgO}_{3} \mathrm{~L}^{-1}$, as amostras não foram tóxicas ao Vibrio fisheri, mostrando que o processo de tratamento do lixiviado pelos três processos realizados $(\mathrm{C} / \mathrm{F}+$ air stripping + ozonização) removeu a toxicidade do lixiviado no ensaio com Vibrio fisheri.

Tabela 2 - Toxicidade do lixiviado bruto e após coagulação/ floculação + air stripping.

\begin{tabular}{l|c} 
Amostra & $\begin{array}{c}\text { Vibrio fisheri } \\
\text { CE50 }(\%)\end{array}$ \\
\hline Lixiviado bruto & 17,66 \\
\hline Lixiviado após coagulação/floculação & 18,27 \\
\hline Lixiviado após coagulação/floculação + air stripping & 32,30 \\
\hline
\end{tabular}




\section{Lodos ativados}

Na Tabela 4, são apresentados os diversos lixiviados pré-tratados e os processos empregados que foram avaliados no processo biológico. Para adaptação do sistema biológico, foi utilizado esgoto sanitário juntamente com lixiviado. Nos testes A, B e C, buscou-se avançar no pré-tratamento, até chegar à ozonização. A Tabela 5 mostra as características do lixiviado pré-tratado em relação às concentrações de nitrogênio amoniacal e DQO.

Os ensaios biológicos foram subdivididos em três testes de bancada, A, B e C, com duração respectiva de 29, 19 e 14 dias. Nos três ensaios biológicos, buscou-se chegar a níveis dos parâmetros analisados abaixo das resoluções CONAMA 430 e INEA 202. O processo biológico se iniciava com o percentual de $10 \%$ de lixiviado e 90\% de esgoto sanitário, aumentando a porcentagem de lixiviado pré-tratado com o tempo de operação dos reatores. Vale ressaltar

Tabela 3 - Toxicidade do lixiviado pré-tratado por coagulação/ floculação + air stripping + ozonização com diferentes doses de ozônio.

\begin{tabular}{l|c} 
Doses de ozônio consumido $\left(\mathrm{mgO}_{3} \cdot \mathrm{L}^{-1}\right)$ & $\begin{array}{c}\text { Vibrio fisheri } \\
\text { CE50 (\%) }\end{array}$ \\
\hline 397 & 88,03 \\
\hline 1.296 & 85,46 \\
\hline $1.648-3.516$ & $\mathrm{NT}$ \\
\hline
\end{tabular}

NT: não tóxico.

Tabela 4 - Lixiviados pré-tratados que foram avaliados no processo biológico.

\begin{tabular}{|c|c|c|c|}
\hline $\begin{array}{l}\text { Teste de } \\
\text { tratabilidade } \\
\text { por processos } \\
\text { biológicos }\end{array}$ & Processo & $\begin{array}{l}\text { Lixiviado } \\
\text { pré-tratado } 1\end{array}$ & $\begin{array}{c}\text { Lixiviado } \\
\text { pré-tratado } 2\end{array}$ \\
\hline Teste A & $\begin{array}{l}\text { Reator } \\
\text { batelada }\end{array}$ & air stripping (A1) & $\begin{array}{c}\mathrm{C} / \mathrm{F}+\text { air stripping } \\
(\mathrm{A} 2)\end{array}$ \\
\hline Teste B & $\begin{array}{l}\text { Reator } \\
\text { batelada }\end{array}$ & $\begin{array}{c}\mathrm{C} / \mathrm{F}+\text { air stripping + } \\
400 \mathrm{mgO}_{3} \cdot \mathrm{L}^{-1}(\mathrm{~B} 1)\end{array}$ & $\begin{array}{l}\mathrm{C} / \mathrm{F}+\text { air stripping + } \\
2400 \mathrm{mgO}_{3} \mathrm{~L}^{-1}(\mathrm{~B} 2)\end{array}$ \\
\hline Teste C & $\begin{array}{c}\text { Reator } \\
\text { batelada } \\
\text { com carvão } \\
\text { ativado }\end{array}$ & $\begin{array}{c}\mathrm{C} / \mathrm{F}+\text { air stripping + } \\
400 \mathrm{mgO}_{3} \cdot \mathrm{L}^{-1}(\mathrm{Cl})\end{array}$ & $\begin{array}{l}\mathrm{C} / \mathrm{F}+\text { air stripping + } \\
2400 \mathrm{mgO}_{3} \mathrm{~L}^{-1}(\mathrm{C} 2)\end{array}$ \\
\hline
\end{tabular}

C/F: coagulação/floculação

Tabela 5 - Características dos lixiviados após os diversos pré-tratamentos (Tabela 4) utilizados nos ensaios A, B e C.

\begin{tabular}{l|c|c|c|c|c|c}
\hline Lixiviado/parâmetro & A1 & A2 & B1 & B2 & C1 & C2 \\
\hline DQO (mg.L-1) & 2.090 & 1.010 & 740 & 580 & 880 & 815 \\
\hline Nitrogênio amoniacal (mg.L-1) & 49 & 47 & 60 & 64 & 70 & 69 \\
\hline
\end{tabular}

que foram mantidos os níveis de lodo biológico de $20 \%$ nos reatores biológicos. A mistura do lixiviado com esgoto doméstico favorece o custo para o tratamento, diminuindo-o significativamente (YE et al., 2014).

Na Figura 5, são exibidas apenas as reduções da DQO do lixiviado, conforme as Equações 1 a 4 . Valores negativos de taxa de remoção de DQO indicam que o lixiviado, além de não ter sido degradado, reduziu a deterioração do esgoto em relação ao reator controle contendo apenas esgoto sanitário. Nos testes A1 e A2 (Figura 5), observam-se remoções menores que 30\% na DQO do lixiviado. Assim, buscou-se ozonizar a amostra de lixiviado, com o objetivo de aumentar a sua biodegradabilidade, apresentando razão de $0,33 \mathrm{DBO}_{5} / \mathrm{DQO}$.

Nos testes B1 e B2 (Figura 5), houve uma maior redução da DQO do lixiviado comparado ao teste A. Os níveis máximos encontrados foram de $65 \%$ de redução de DQO quando o reator continha $20 \%$ de lixiviado ozonizado e $80 \%$ de esgoto sanitário (B2). Quando se aumentou o volume de lixiviado ozonizado dentro do reator para $30 \%$, houve uma redução drástica na remoção da DQO do lixiviado. Portanto, fica claro que, apesar de o lixiviado ter passado por vários pré-tratamentos, ainda apresentava recalcitrância e toxicidade ao lodo biológico.

Nos testes C1 e C2 (Figura 5), adicionou-se carvão ativado em pó no reator biológico para possibilitar uma maior remoção de DQO do lixiviado, uma vez que a utilização do carvão ativado em conjunto com o lodo biológico pode propiciar a remoção de compostos recalcitrantes (LI et al., 2010). Observou-se uma melhora das propriedades de sedimentação da biomassa (WISZNIOWSKI et al., 2007). Com a adição de carvão ativado ao reator biológico, o sistema se manteve mais estável, porém o nível máximo de redução da DQO do lixiviado pré-tratado por $\mathrm{C} / \mathrm{F}+$ air stripping + ozonização $\left(400 \mathrm{mgO}_{3} \cdot \mathrm{L}^{-1}\right)$ chegou a $50 \%(\mathrm{C} 1)$.

Vale ressaltar que houve a necessidade da adição de alíquotas de lodo biológico durante o período do ensaio, para manter os níveis em $20 \%$ de lodo biológico dentro do reator. Essa redução do volume do lodo se deve, provavelmente, à recalcitrância do lixiviado.

$\mathrm{O}$ processo biológico apresentou resultados excelentes para redução de nitrogênio amoniacal, principalmente nos Testes A e C, que ficaram abaixo dos valores limite no CONAMA 430/2011 e INEA 202, 20 mg.L. $\mathrm{L}^{-1}$ e $5 \mathrm{mg} . \mathrm{L}^{-1}$, respectivamente. O desempenho menos satisfatório foi obtido no teste $\mathrm{B}$, provavelmente devido ao elevado teor de nitrogênio amoniacal presente no esgoto sanitário, que foi de $135 \mathrm{mg} . \mathrm{L}^{-1}$, diferente dos Testes $\mathrm{A}$ e C, que apresentaram 49 e $78 \mathrm{mg} . \mathrm{L}^{-1}$, respectivamente. A Tabela 6 apresenta a média de entrada, saída e do percentual de remoção de nitrogênio amoniacal nos testes A, B e C. 


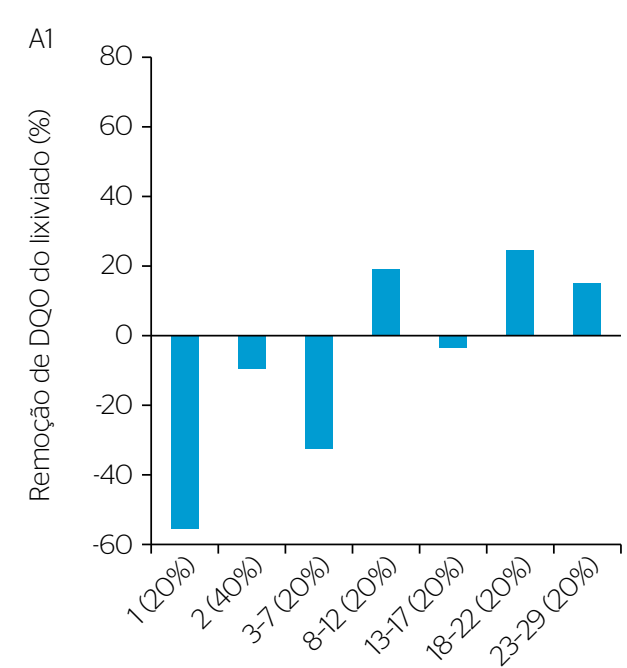

Dias (\% de lixiviado no reator)

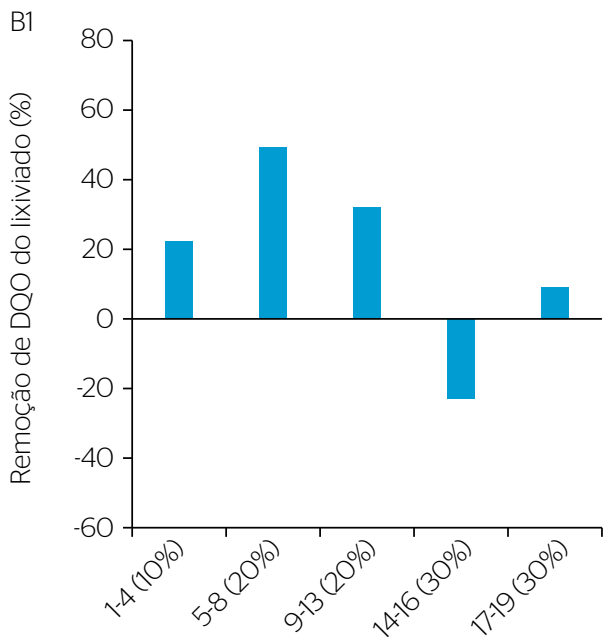

Dias (\% de lixiviado no reator)

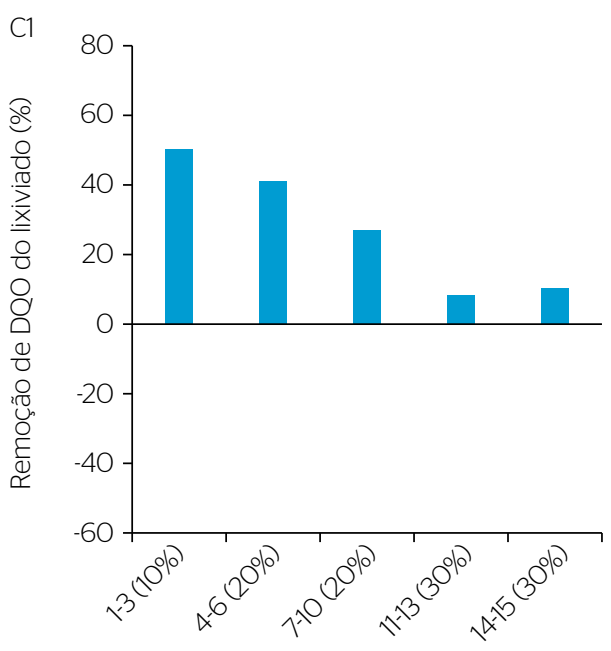

Dias (\% de lixiviado no reator)

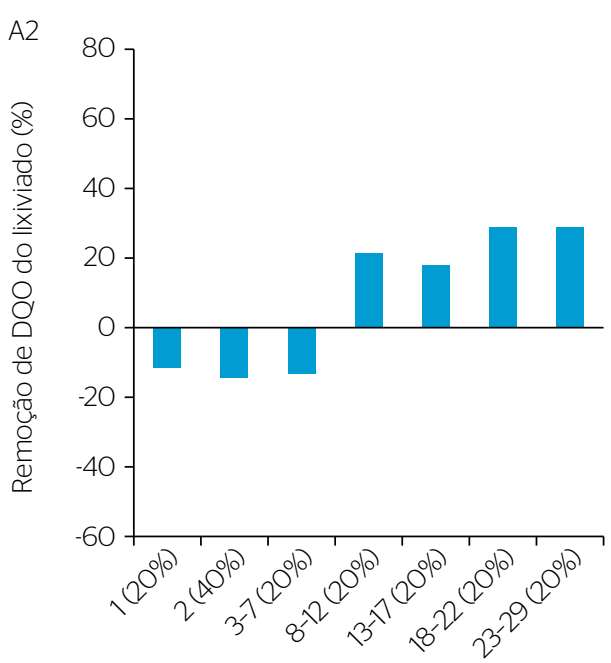

Dias (\% de lixiviado no reator)

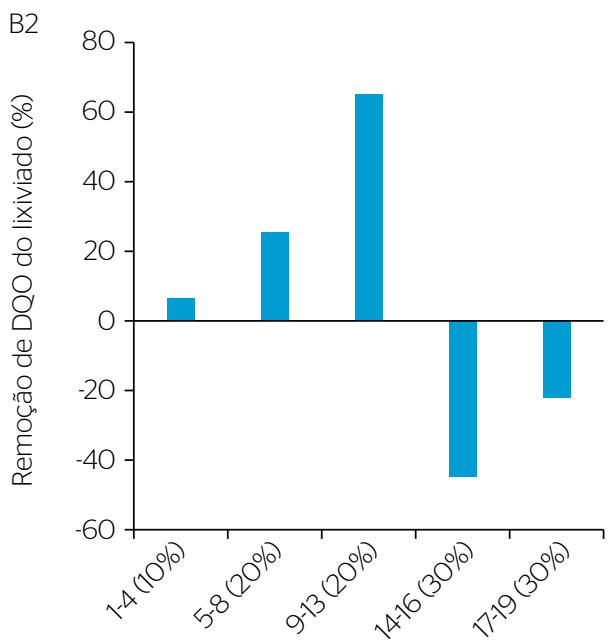

Dias (\% de lixiviado no reator)

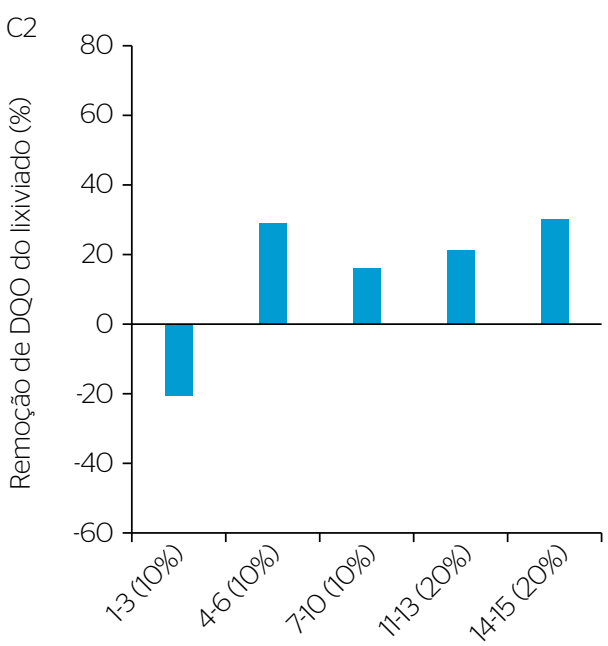

Dias (\% de lixiviado no reator)

Figura 5 - Redução de demanda química de oxigênio no processo biológico do lixiviado pré-tratado com air stripping (A1), com coagulação/floculação + air stripping (A2), com coagulação/floculação + air stripping $+400 \mathrm{mgO}_{3} \cdot \mathrm{L}^{-1}$ (B1), com coagulação/floculação + air stripping + 2.400 mgO $\mathrm{L}^{-1}$ (B2), com coagulação/floculação + air stripping + $400 \mathrm{mgO}_{3} \mathrm{~L}^{-1}(\mathrm{C} 1)$ e com coagulação/floculação + air stripping + $2.400 \mathrm{mgO}_{3} \mathrm{~L}^{-1}(\mathrm{C} 2) \mathrm{com}$ carvão ativado em pó dentro do reator. 
Tabela 6 - Nitrogênio amoniacal do lixiviado na entrada e saída nos reatores biológicos e percentuais de redução de nitrogênio amoniacal.

\begin{tabular}{l|c|c|c} 
Teste & $\begin{array}{c}\text { Média de entrada } \\
\text { com desvio } \\
\text { padrão }\left(\text { mg. }^{-1}\right)\end{array}$ & $\begin{array}{c}\text { Média de saída } \\
\text { com desvio } \\
\text { padrão }\left(\text { mg. } \mathrm{L}^{-1}\right)\end{array}$ & $\begin{array}{c}\text { Percentual de } \\
\text { redução médio (\%) }\end{array}$ \\
\hline A1 & $35,9 \pm 6,1$ & $4,3 \pm 1,3$ & $87,8 \pm 4,9$ \\
\hline A2 & $50,7 \pm 3,9$ & $3,6 \pm 1,0$ & $92,9 \pm 2,3$ \\
\hline B1 & $88,8 \pm 37,3$ & $21,0 \pm 19,0$ & $77,5 \pm 15,2$ \\
\hline B2 & $90,0 \pm 36,4$ & $24,0 \pm 26,7$ & $76,8 \pm 20,5$ \\
\hline C1 & $70,9 \pm 5,2$ & $2,4 \pm 1,2$ & $96,6 \pm 1,8$ \\
\hline C2 & $69,2 \pm 5,9$ & $2,4 \pm 1,2$ & $96,5 \pm 1,9$ \\
\hline
\end{tabular}

\section{CONCLUSÕES}

O lixiviado bruto utilizado nos experimentos apresentou recalcitrância, alta concentração de nitrogênio amoniacal e elevada toxicidade. $\mathrm{O}$ processo de $\mathrm{C} / \mathrm{F}$ apresentou excelente resultado, com a maior redução de DQO, aproximadamente $60 \%$.

A remoção de nitrogênio amoniacal por air stripping apresentou os níveis almejados, mostrando-se ser de fácil controle e possibilitando sua adequação aos níveis desejados. A ozonização propiciou aumento na biodegradabilidade e reduziu a toxicidade a níveis não tóxicos. O conjunto dos processos de tratamento aqui realizado propicia um lixiviado isento de toxicidade ao Vibrio fisheri, principalmente através da ozonização.

Os processos biológicos apresentaram variações nas eficiências de tratamento em função do pré-tratamento. A eficiência máxima global foi obtida no teste B2, com 90,6\% de remoção de DQO em relação ao lixiviado bruto. Já o lodo ativado com carvão ativado apresentou eficiência máxima global no teste $\mathrm{C} 1$, com $81,5 \%$.

É importante ressaltar que, apesar de o lixiviado ter passado pelos pré-tratamentos de $\mathrm{C} / \mathrm{F}$ + air stripping + ozonização, não apresentar toxicidade ao Vibrio fischeri e ter boa razão $\mathrm{DBO}_{5} / \mathrm{DQO}$, ainda assim impactou o processo biológico quando na proporção de 30\% (30\% de lixiviado pré-tratado $+70 \%$ de esgoto sanitário). Esses resultados revelam a dificuldade de tratamento desse lixiviado e apontam para uma máxima diluição desse lixiviado pré-tratado de $20 \%$ em uma estação de tratamento de esgoto. Dessa forma, fica clara a importância de estudos detalhados para avaliar o real impacto da diluição de lixiviados pré-tratados nessas estações.

\section{REFERÊNCIAS}

AMERICAN PUBLIC HEALTH ASSOCIATION (APHA); AMERICAN WATER WORKS ASSOCIATION (AWWA); WATER POLLUTION CONTROL FEDERATION (WPCF). (2005) Standard Methods for the Examination of Water and Wastewater. 20. ed. Washington, D.C.: APHA; AWWA; WPCF.

AMOR, C:; TORRES-SOCÍAS, E.; PERES, J.A.; MALDONADO, M.I.; OLLER, I.; MALATO, S.; LUCAS, M.S. (2015) Mature landfill leachate treatment by coagulation/flocculation combined with Fenton and solar photo-Fenton processes. Journal of Hazardous Materials, v. 286. p. 261-268. https://doi.org/10.1016/j.jhazmat.2014.12.036

AMR, S.S.A.; AZIZ, H.A.; ADLAN, M.N.; BASHIR, M.J.K. (2013) Pretreatment of stabilized leachate using ozone/persulfate oxidation process. Journal of Hazardous Materials, v. 221, p. $492-499$. http://dx.doi.org/10.1016/j.cej.2013.02.038

ANFRUNS, A.; GABARRÓ, J.; OLMOS, R.G.; PUIG, S.; BALAGUER, M.D.; COLPRIN, J. (2013) Coupling anammox and advanced oxidationbased technologies for mature landfill leachate treatment. Journal of Hazardous Materials, v. 258-259, p. 27-34. https://doi.org/10.1016/j. jhazmat.2013.04.027

ASSOCIAÇÃO BRASILEIRA DE NORMAS TÉCNICAS (ABNT). (2012) NBR 15411-3: Vibrio fischeri - ensaio de toxicidade aguda. Rio de Janeiro: ABNT.
BACCOT, C; PALLIER, V; FEUILLADE-CATHALIFAUD, G. (2017) Biochemical methane potential of fractions of organic matter extracted from a municipal solid waste leachate: Impact of their hydrophobic character. Waste Management. https://doi. org/10.1016/j.wasman.2016.11.025

BIALOWIEC, A.; BARYLA, I.W.; AGOPSOWICZ, M. (2007) The efficiency of evapotranspiration of landfill leachate in the soil-plant system with willow Salix amygdalina L. Ecological Engineering, v. 30, p. 356-361. http://dx.doi.org/10.1016/j.ecoleng.2007.04.006

BILA, D.M. (2000) Aplicação de processos combinados no tratamento de chorume. Dissertação (Mestrado em Engenharia Química) - Universidade do Rio de Janeiro, Rio de Janeiro.

BILIŃSKA, L.; GMUREK, M.; LEDAKOWICZ, S. (2016) Comparison between industrial and simulated textile wastewater treatment by AOPs - Biodegradability, toxicity and cost assessment. Chemical Engineering Journal, v. 306, p. 550-559. https://doi.org/10.1016/j. cej.2016.07.100

BRASIL. (2011) Resolução CONAMA no 430/2011, de 13 de maio de 2011. Dispõe sobre as condições e padrões de lançamento de efluentes, complementa e altera a Resolução no 357, de 17 de março de 2005, do Conselho Nacional do Meio Ambiente CONAMA. Diário Oficial da União, n. 92, p. 89. 
CASSANO, D.; ZAPATA, A.; BRUNETTI, G.; MORO, D.; IACONI, C.D.; OLLER, I.; MALATO, S.; MASCOLO, G. (2011) Comparison of several combined/integrated biological-AOPs setups for the treatment of municipal landfill leachate: Minimization of operating costs and effluent toxicity. Chemical Engineering Journal, v. 172, p. 250-257. http://dx.doi.org/10.1016/j.cej.2011.05.098

CHING, H.W.; TANAKA, T.S.; ELIMELECH, M. (1994) Dynamics of coagulation of kaolin particles with ferric chloride. Water Research, v. 28, p. 559-569. https://doi.org/10.1016/0043-1354(94)90007-8

CORTEZ, S.; TEIXEIRA, P;; OLIVEIRA, R.; MOTA, M. (2O11) Evaluation of Fenton and ozone-based advanced oxidation processes as mature landfill leachatepre-treatments.Journal of EnvironmentalManagement, v. 92, p. 749-755. https://doi.org/10.1016/j.jenvman.2010.10.035

DUNN, O.J. (1964) Multiple Comparisons Using Rank Sums. Technometric, v. 6, p. 241-252. https://doi.org/10.2307/1266041

GOTTSCHALK, C.; LIBRA, J.A.; SAUPE, A. (2010) Ozonation of Water and Waste Water - A Practical Guide to Understand Ozone and its Applications. 2. ed. Weinheim: Wiley-VCH Verlga GmbH \& Co.

GUO, J.S.; ABBAS, A.A.; CHEN, Y.P.; LIU, Z.P.; FANG, F.; CHEN, P. (2O10) Treatment of landfill leachate using a combined stripping, Fenton, SBR, and coagulation process. Journal of Hazardous Materials, v. 178. p. 699-705. https://doi.org/10.1016/j.jhazmat.2010.01.144

HASAR, H.; UNSAL, S.A.; IPEK, U.; KARATAS, S.; CINAR, O.; YAMAN, C.; KINACl, C. (2009) Stripping/flocculation/membrane bioreactor/ reverse osmosis treatment of municipal landfill leachate. Journal of Hazardous Materials, v. 171, p. 309-317. https://doi.org/10.1016/j. jhazmat.2009.06.003

HUANG, D.; HU, C.; ZENG, C.H.G.; CHENG, M.; XU, P.; GONG, X:; WANG, R.; XUE, W. (2017) Combination of Fenton process and biotreatment for wastewater treatment and soil remediation. Science of the Total Environment, v. 574, p. 1599-1610. https://doi. org/10.1016/j.scitotenv.2016.08.199

IACONI, C. (2012) Biological treatment and ozone oxidation: Integration or coupling. Bioresource Technology, v. 106, p. 63-68. https://doi.org/10.1016/j.biortech.2011.12.007

LI, X.Z:; ZHAO, Q.L.; HAO, X.D. (1999) Ammonium removal from landfill leachate by chemical precipitation. Waste Management, v. 19, p. 409-415. http://dx.doi.org/10.1016/S0956-053X(99)00148-8

LI, W.; HUA, T.; ZHOU, Q; ZHANG, S.; LI, F. (2010) Treatment of stabilized landfill leachate by the combined process of coagulation/ flocculation and powder activated carbon adsorption. Desalination, v. 264, p. 56-62. http://dx.doi.org/10.1016/j.desal.2010.07.004

LIU, X.; LI, X.M.; YANG, Q:; YUE, X:; SHEN, T.T.; ZHENG, W.; LUO, K.; SUN, Y.H.:ZENG, G.M.(2O12) Landfill leachate pretreatment by coagulationflocculation process using iron-based coagulants: Optimization by response surface methodology. Chemical Engineering Journal, v. 200, p. 39-51. http://dx.doi.org/10.1016/j.cej.2012.06.012

MAHMUD, K.; HOSSAIN, M.D.; SHAMS, S. (2O12) Different treatment strategies for highly polluted landfill leachate in developing countries. Waste Management, v. 32, p. 2096-2105. https://doi. org/10.1016/j.wasman.2011.10.026

MARAÑÓN, E.; CASTRILLOON, L.; NAVA, Y.F;: MÉNDEZ, A.F.; SANCHEZ, A.F. (2008) Coagulation-flocculation as a pretreatment process at a landfill leachate nitrification-denitrification plant. Journal of Hazardous Materials, v. 156, p. 538-544. https://doi.org/10.1016/j. jhazmat.2007.12.084

MOREIRA, F.C.; SOLER, J; FONSECA, A.; SARAIVA, I.; BOAVENTURA, R.A.R.; BRILLAS, E.; VILAR, V.J.P. (2O16) Electrochemical advanced oxidation processes for sanitary landfill leachate remediation: Evaluation of operational variables. Applied Catalysis B. Environmental, v. 182, p. 161-171. http://dx.doi.org/10.1016/j. apcatb.2015.09.014

PALMA, L.D.; FERRANTELLI, P.; MERLI, C.; PETRUCCI, E. (2002) Treatment of industrial landfill leachate by means of evaporation and reverse osmosis. Waste Management, v. 22, p. 951-955. https:// doi.org/10.1016/S0956-053X(O2)00079-X

R CORE TEAM. (2017) R: A language and environment for statistical computing. R Foundation for Statistical Computing. Viena. Disponível em: <https://www.R-project.org/>. Acesso em: 12 mar 2017.

RENOU, S.; GIVAUDAN, J.G.; POULAIN, S.; DIRASSOUYAN, F.; MOULIN, P. (2008) Landfill leachate treatment: Review and opportunity. Journal of Hazardous Materials, v. 150, p. 468-493. https://doi.org/10.1016/j.jhazmat.2007.09.077

RIO DE JANEIRO. (1986) Diretriz Instituto Nacional de Ambiente, NT-2O2.R-10, de 13 de maio de 1986. Dispõe sobre critérios e padrões para lançamento de efluentes líquidos. Diário Oficial do Rio de Janeiro. p. 2.

SANTOS, D.C.; SILVA, L.; ALBUQUERQUE, A.; SIMÕES, R.; GOMES A.C. (2013) Biodegradability enhancement and detoxification of cork processing wastewater molecular size fractions by ozone Bioresource Technology, v. 147, p. 143-151. https://doi.org/10.1016/j. biortech.2013.07.154

SILVA, A.C.; DEZOTTI, M.; SANT'ANNA JR., G.L. (2004) Treatment and detoxification of a sanitary landfill leachate. Chemosphere, v. 55, p. 207-214. https://doi.org/10.1016/j.chemosphere.2003.10.013

SILVA, F.C.V;; FONSECA, A.; SARAIVA, A.I.; BOAVENTURA, R.A.R.; VILAR, J.P.V. (2016) Scale-up and cost analysis of a photo-Fenton system for sanitary landfill leachate treatment, Chemical. Chemical Engineering Journal, v. 283, p. 76-88. http://dx.doi.org/10.1016/j. сеј.2015.07.063

SINGH, S.K.; TOWNSEND, T.G.; BOYER, T.H. (2012) Evaluation of coagulation $\left(\mathrm{FeCl}_{3}\right.$ ) and anion exchange (MIEX) for stabilized landfill leachate treatment and high-pressure membrane pretreatment. Separation and Purification Technology, v. 96, p. 98-106. http:// dx.doi.org/10.1016/j.seppur.2012.05.014

SOBECKA, B.S.; TOMASZEWSKA, M.; MORAWSKI, A. (2006) Removal of humic acids by the ozonation-biofiltration process. Desalination, v. 198, p. 265-273. https://doi.org/10.1016/j.desal.2006.01.027 
SYAFALNI; LIM, H.K.; ISMAIL, N.; ABUSTAN, I.; MURSHED, M.F.; AHMAD, A. (2012) Treatment of landfill leachate by using lateritic soil as a natural coagulant. Journal of Environmental Management, v. 112, p. 353-359. https://doi.org/10.1016/j.jenvman.2012.08.001

THEEPHARAKSAPAN, S.; CHIEMCHAISRI, C.; CHIEMCHAISRI, W.; YAMAMOTO, K. (2011) Removal of pollutants and reduction of biotoxicity in a full scale chemical coagulation and reverse osmosis leachate treatment system. Bioresource Technology, v. 102, p. 5381-5388. https://doi.org/10.1016/j.biortech.2010.11.091

THEODORSSON-NORHEIM, E. (1986) Kruskal-Wallis test: Basic computer program to perform nonparametric one-way analysis of variance and multiple comparisons on ranks of several independent samples. Computer Methods Programs Biomed, v. 23, p. 57-62.

VEDRENNE, M.; MEDRANO, R.V.; GARCIA, D.P.; URIBE, B.A.F.; IBANEZ, J.G. (2012) Characterization and detoxification of a mature landfill leachate using a combined coagulation-flocculation/photo Fenton treatment. Journal of Hazardous Materials, v. 205-206, p. 208-215. https://doi.org/10.1016/j.jhazmat.2011.12.060

VELASQUEZ, O.M.T; RAMIREZ, I.M. (2006) Combined pretreatment of coagulation-ozonation for Saline stabilized landfill leachates. Ozone: Science and Engineering, v. 28, p. 309-316. https:// doi.org/10.1080/01919510600900241

WISZNIOWSKI, J.; GÓRSKA, J.S.; ROBERT, D.; WEBER, J.V. (2007) The effect of landfill leachate composition on organics and nitrogen removal in an activated sludge system with bentonite additive. Journal of Environmental Management, v. 85, p. 59-68. https://www. sciencedirect.com/science/article/pii/SO301479706002222
YE, Z.L.; XIE, X.; DAI, L.; WANG, Z.; WU, W.; ZHAO, F.; XIE, X.; HUANG, S.; LIU, M.; CHEN, S. (2014) Full-scale blending treatment of fresh MSWI leachate with municipal wastewater in a wastewater treatment plant. Waste Management, v. 34, p. 2305-2311. https://doi. org/10.1016/j.wasman.2014.06.019

ZHANG, F.; PENG, Y.; MIAO, L.; WANG, Z.; WANG, S.; LI, B. (2017) A novel simultaneous partial nitrification Anammox and denitrification (SNAD) with intermittent aeration for cost-effective nitrogen removal from mature landfill leachate. Chemical Engineering Journal, v. 313, p. 619-628. http://dx.doi.org/10.1016/j.cej.2016.12.105

ZHANG, Q.; DOR, L.; ZHANG, L.; YANG, W.; BLASIAK, W. (2O12) Performance analysis of municipal solid waste gasification with steam in a Plasma Gasification Melting reactor. Applied Energy, v. 98, p. 219-229. http://dx.doi.org/10.1016/j.apenergy.2012.03.028

ZHANG, T.; DING, L.; REN, H. (2009) Pretreatment of ammonium removal from landfill leachate by chemical precipitation. Journal of Hazardous Materials, v. 166, p. 911-915. https://www.sciencedirect. com/science/article/pii/SO304389408017998

ZHOU, B.; YU, Z.; WEI, Q.; LONG, H.; XIE, Y.; WANG, Y. (2016) Electrochemical oxidation of biological pretreated and membrane separated landfill leachate concentrates on boron doped diamond anode. Applied Surface Science, v. 377, p. 406-415. https://doi. org/10.1016/j.apsusc.2016.03.045

ZOLFAGHARI, M.; DROGUIA, P.; BRAR, S.K.; BUELNA, G.; DUBÉ, R. (2O16) Effect of bioavailability on the fate of hydrophobic organic compounds and metal in treatment of young landfill leachate by membrane bioreactor. Chemosphere, v. 161, p. 390-399. https://doi. org/10.1016/j.chemosphere.2016.07.021 